\title{
Anesthetic Care During Tracheostomy in a Patient with Generalized Tetanus: A Case Report
}

\author{
Megumi Yoshida (D) \\ Yoshikazu Yamaguchi (D) \\ Mizuho Matsushital \\ Sayaka Tsuboi' \\ Yoh Sugawara' \\ Hajime Hayami ${ }^{\text {I }}$ \\ Joseph Tobias (iD ${ }^{2}$ \\ Gaku Inagawa (D) \\ 'Department of Anesthesiology, \\ Yokohama Municipal Citizen's Hospital, \\ Yokohama, Japan; ${ }^{2}$ Department of \\ Anesthesiology \& Pain Medicine, \\ Nationwide Children's Hospital and The \\ Ohio State University, Columbus, \\ $\mathrm{OH}$, USA
}

\begin{abstract}
Tetanus is a potentially fatal infectious disease caused by the toxins produced by the anaerobic bacterium, Clostridium tetani. Of major concern during the perioperative care of these patients is control of muscle spasms, skeletal rigidity, and autonomic dysfunction. Several of the modern sedative and opioid agents including remifentanil have not been fully evaluated in managing tetanus. We present the intraoperative use of remifentanil in a 75-year -old woman with generalized tetanus who required anesthetic care during placement of a tracheostomy. The end-organ involvement of tetanus is presented, previous reports of anesthetic care reviewed, and the potential utility of remifentanil explored.
\end{abstract}

Keywords: tetanus, tracheostomy, general anesthesia

\section{Introduction}

Tetanus is a fatal infectious disease caused by the toxins, tetanospasmin and tetanolysin, produced by the anaerobic bacterium, Clostridium tetani. ${ }^{1}$ Generalized tetanus with skeletal muscle rigidity, muscle spasms, and autonomic nerve dysfunction frequently requires endotracheal intubation and mechanical ventilation with deep sedation and neuromuscular blockade. Mechanical ventilation may be required in up to $77.5 \%$ of the patients with tetanus with a median duration of ventilation of 23 days, and $80 \%$ of the patients requiring tracheostomy. Although the mortality of severe tetanus is as high as $37-50 \%$ in low-income and middleincome countries, the in-hospital mortality has been reported to be $6.8 \%$ in Japan. ${ }^{1,2}$

The ICU and anesthetic care of patients with generalized tetanus may be complicated by difficulties with control of the autonomic dysfunction and skeletal muscle rigidity. Several of the modern sedative and opioid agents including remifentanil have not been fully evaluated in managing tetanus. We present the intraoperative use of remifentanil in a 75-year-old woman with generalized tetanus who required anesthetic care during placement of a tracheostomy. The end-organ involvement of tetanus is presented, previous reports of anesthetic care reviewed, and the potential utility of remifentanil explored. Presentation of this case report is in line with the guidelines of the Institutional Review Board of Yokohama Municipal Citizen's Hospital (Yokohama, Japan). Written Informed consent for publication was obtained from the patient.

\section{Case Presentation}

The patient was a 75-year-old, 72-kg woman who presented for surgical tracheostomy for the management of generalized tetanus. Her past medical history was significant for 
bronchial asthma and hypertension. Her medication regimen included nifedipine $10 \mathrm{mg}$ once a day, trichlormethiazide $1 \mathrm{mg}$ once a day, pranlukast hydrate $112.5 \mathrm{mg}$ twice a day, theophylline $400 \mathrm{mg}$ twice a day, cloperastine hydrochloride $40 \mathrm{mg}$ twice a day, and dimethicone $240 \mathrm{mg}$ three times a day. Five days prior to hospital admission, she suffered a laceration to her right heel. As she had not been recently vaccinated against tetanus, 1500 units of human tetanus immunoglobulin were administered. However, signs and symptoms progressed and she was admitted to the intensive care unit (ICU) because of severe trismus, generalized spasticity, dysphagia, and violent autonomic disturbances involving the cardiovascular system. Her trachea was intubated, mechanical ventilation initiated, and plans made for a surgical tracheostomy on the second day. Her medication regimen in the ICU included fentanyl (35 $\mu \mathrm{g} / \mathrm{hr})$, propofol $(2 \mathrm{mg} / \mathrm{kg} / \mathrm{hr})$, dexmedetomidine $(0.2 \mu \mathrm{g} /$ $\mathrm{kg} / \mathrm{hr})$, midazolam (0.05 mg/kg/hr), landiolol (1 $\mu \mathrm{g} / \mathrm{kg} / \mathrm{min})$, and magnesium sulfate of $(0.5 \mathrm{~g} / \mathrm{hr})$. The serum magnesium level was $6.9 \mathrm{mg} / \mathrm{dL}$ on the day of surgery. Despite the continuous infusion of these sedative and analgesic agents as well as the supra-therapeutic magnesium level, she had episodes of sudden autonomic dysfunction with a rapid increase in her systolic blood pressure to $\geq 200 \mathrm{mmHg}$ several times per day. A transthoracic echocardiography revealed normal ventricular contractility. Tracheostomy was performed on the seventh day. She was transported to the operating room, and routine American Society of Anesthesiologists' monitors were placed. A bolus of propofol (30 mg) and rocuronium (30 mg) were administered prior to the transfer to the operating room table. General anesthesia was maintained with total intravenous anesthesia (TIVA) using a continuous infusion of propofol (3 $\mathrm{mg} / \mathrm{kg} / \mathrm{hr}$ ), remifentanil $(0.1-0.25 \mu \mathrm{g} / \mathrm{kg} / \mathrm{min})$, and rocuronium $(0.8 \mathrm{mg} / \mathrm{kg} / \mathrm{hr})$. Landiolol and the magnesium sulfate infusion were continued during the procedure. The systolic blood pressure ranged from 90 to $120 \mathrm{mmHg}$ with a heart rate of 45-55 beats/minute. The surgical procedure required approximately 30 minutes. Remifentanil was discontinued at the end of the surgery. Postoperative sedative and analgesia agents included $2 \mathrm{mg} / \mathrm{kg} / \mathrm{hr}$ of propofol, $35 \mu \mathrm{g} / \mathrm{hr}$ of fentanyl, $0.2 \mu \mathrm{g} / \mathrm{kg} / \mathrm{hr}$ of dexmedetomidine, and $0.1 \mathrm{mg} / \mathrm{kg} / \mathrm{hr}$ of midazolam. Despite continuing these sedative and analgesic infusions, hypertension and tachycardia were intermittently observed after the patient was transported back to the ICU. However, these hemodynamic changes did not require further pharmacologic treatment. The continuous infusion of midazolam was discontinued on the 32 nd hospital day. The continuous infusions of propofol and fentanyl were discontinued on the 37 th hospital day. After that time, the patient was transitioned from mechanical ventilation to spontaneous ventilation, and subsequently transferred to the general inpatient ward from the ICU on the 41st hospital day. Although she needed a continuous rehabilitation program to recover motor function, she recovered without neurological deficit. She was discharged from the hospital and transferred to the rehabilitation hospital on the 69th day of hospitalization.

\section{Discussion}

The clinical features of tetanus are caused by tetanospasmin (a metalloprotease). It enters the peripheral nervous system directly from the contaminated wound, affecting the function and transmission of motor, sensory, and autonomic neurons. Tetanospasmin travels through axons in a retrograde fashion to the central nervous system (CNS). Radiolabelled assays have demonstrated that tetanospasmin has a preference for inhibitory motor neurons, which explains the clinical picture of muscle rigidity. The tetanus toxin disturbs formation of the soluble N-ethylmaleimide-sensitive factor attachment protein receptor (SNARE) complex, which decreases motor nerve inhibition, resulting in the characteristic muscle spasm. ${ }^{3}$ Tetanus toxin also has activity at the central excitatory synapses, binding to sympathetic adrenergic neurons, leading to autonomic dysregulation and episodes of hypertension. ${ }^{4}$

During anesthetic care of patients with severe tetanus, control of skeletal muscular rigidity, muscle spasms, and autonomic dysfunction may be problematic., ${ }^{5,6}$ As the majority of reports of anesthetic care for such patients are anecdotal, there is limited evidence-based medicine to guide clinical practice. Additionally, as many of these reports are from developing countries, there is limited experience with novel sedative and opioid agents such as remifentanil. To date, the benzodiazepines remain the primary agents that have been used most commonly to control muscle spasms and rigidity related to tetanus., Neuromuscular blocking agents may be added when sedatives are ineffective enough. Recently, anecdotal information from single-case reports or case series have demonstrated the potential utility of dexmedetomidine $(0.2-0.7 \mu \mathrm{g} / \mathrm{kg} / \mathrm{hr})$ to control muscle spasms and autonomic dysfunction. 8,9

Remifentanil is a selective mu-opioid receptor agonist, which has a rapid onset of action and is metabolized by non-specific ester hydrolysis in the blood and tissues. ${ }^{10}$ During surgical procedures, noxious stimuli and surgical incision may precipitate muscle spasms and autonomic dysfunction. Potent opioids such as fentanyl and its derivatives are frequently used to blunt the surgical stress 
response and the response to noxious surgical stimuli. In our patient, remifentanil was discontinued in the OR because continuous infusion of remifentanil is forbidden in Japan. Although other sedative agents were administered in the ICU, her cardiovascular status was more stable during the remifentanil infusion in the OR than in the ICU.

In our patient, autonomic dysfunction and muscle rigidity persisted despite the administration of propofol, dexmedetomidine, and midazolam during her initial time in the ICU. Therefore, a magnesium sulphate infusion was added with limited efficacy in an attempt to control these clinical manifestations of tetanus. ${ }^{11,12}$ Despite its limited efficacy in our patient, magnesium sulphate was routinely used to control muscle rigidity and autonomic dysfunction with tetanus as it may reduce the requirement for other medications in this clinical setting. ${ }^{12,13}$ Although not noted in our patient, potential concerns regarding the administration of magnesium include skeletal muscle weakness, sedation, hypotension, and bradyarrhythmias. ${ }^{13}$

Given the persistence of clinical symptoms of tetanus despite the administration of midazolam, fentanyl, propofol, dexmedetomidine, magnesium, and landiolol; a remifentanil infusion was added to control the surgical stress response during tracheostomy. Although we noted no hemodynamic effects of the remifentanil infusion, its short-life allows for rapid dissipation of its clinical effects if hemodynamic depression is noted. Additionally, as a potent $\mu$-agonist, it effectively controls the response to surgical manipulation.

To date, we could find only one previous report regarding the use of remifentanil in a patient with tetanus. Beecroft et al reported the use of a remifentanil to control the systemic manifestations of severe generalized tetanic spasms in a 61-year-old woman which were refractory to infusions of propofol, midazolam, alfentanil, magnesium sulphate, and atracurium. ${ }^{10}$ The muscle spasms were severe enough to result in chest wall rigidity, which compromised mechanical ventilation even with manual bag-valve ventilation, occurring in response to even minor stimuli. A remifentanil infusion was started at $0.05-0.1 \mu \mathrm{g} / \mathrm{kg} / \mathrm{min}$. The infusion rate was increased prior to any therapies and titrated to effect $(0.3-0.6 \mu \mathrm{g} / \mathrm{kg} / \mathrm{min})$. This controlled the muscle spasms sufficiently to allow therapy to continue without the need for neuromuscular blockade and a reduction of the propofol infusion to $0.5-2 \mathrm{mg} / \mathrm{kg}$ / $\mathrm{hr}$. The propofol and remifentanil infusions were continued for a total of 2 weeks. After cessation of sedation, there were concerns regarding the patient's neurologic status and a potential hypoxic brain injury. The patient subsequently developed severe bronchopneumonia, and in view of the associated concerns regarding brain injury, treatment was not escalated and the patient expired on day $18 .{ }^{10}$

In summary, our case and the report of Beecroft et al demonstrate anecdotal experience regarding the potential efficacy of remifentanil in controlling the autonomic dysfunction and muscle spasms associated with tetanus. Given its potent effects as a $\mu$-agonist, it provides intense analgesia to both noxious and surgical stimuli. Its short half-life allows for rapid titration by continuous infusion, thereby making in a potentially useful adjunct to other agents commonly used to control the clinical manifestations of tetanus.

\section{Abbreviations}

ICU, intensive care unit; TIVA, total intravenous anesthesia; CNS, central nervous system; SNARE, soluble $\mathrm{N}$-ethylmaleimide-sensitive factor attachment protein receptor.

\section{Funding}

There is no funding to report.

\section{Disclosure}

The authors do not have conflicts of interest.

\section{References}

1. Yen LM, Thwaites CL. Tetanus. Lancet. 2019;393(10181):1657-1668. doi:10.1016/S0140-6736(18)33131-3

2. Nakajima M, Aso S, Matsui H, Fushimi K, Yasunaga H. Clinical features and outcomes of tetanus: analysis using a national inpatient database in Japan. J Crit Care. 2018;44:388-391. doi:10.1016/j. jcrc.2017.12.025

3. Schiavo G, Benfenati F, Poulain B, et al. Tetanus and botulinum-B neurotoxins block neurotransmitter release by proteolytic cleavage of synaptobrevin. Nature. 1992;359(6398):832-835. doi: $10.1038 / 359832 \mathrm{a} 0$

4. Schiavo G, Matteoli M, Montecucco C. Neurotoxins affecting neuroexocytosis. Physiol Rev. 2000;80(2):717-766. doi:10.1152/ physrev.2000.80.2.717

5. Tobias JD. Anesthetic implications of tetanus. South Med J. 1998;91 (4):384-387. doi:10.1097/00007611-199804000-00015

6. Mahajan R, Kumar A, Singh SK. General anesthesia in tetanus patient undergoing emergency surgery: a challenge for anesthesiologist. Anesth Essays Res. 2014;8(1):96-98. doi:10.4103/0259-1162.128922

7. Okoromah CN, Lesi FE. Diazepam for treating tetanus. Cochrane Database Syst Rev. 2004;(1):Cd003954. doi:10.1002/14651858. CD003954.pub2

8. Girgin NK, Iscimen R, Gurbet A, Kahveci F, Kutlay O. Dexmedetomidine sedation for the treatment of tetanus in the intensive care unit. Br J Anaesth. 2007;99(4):599-600. doi:10.1093/bja/aem251

9. Miya K, Shimojo N, Koyama Y, et al. Efficacy of concomitant use of dexmedetomidine and propofol in tetanus. Am J Emerg Med. 2015;33 (12):1848, e1843-e1844. doi:10.1016/j.ajem.2015.04.069 
10. Beecroft CL, Enright SM, O'Beirne HA. Remifentanil in the management of severe tetanus. Br J Anaesth. 2005;94(1):46-48. doi:10.1093/ bja/aeh288

11. Rodrigo C, Fernando D, Rajapakse S. Pharmacological management of tetanus: an evidence-based review. Crit Care. 2014;18(2):217. doi:10.1186/cc13797
12. Thwaites CL, Yen LM, Loan HT, et al. Magnesium sulphate for treatment of severe tetanus: a randomised controlled trial. Lancet. 2006;368(9545):1436-1443. doi:10.1016/S0140-6736(06)69444-0

13. Cook TM, Protheroe RT, Handel JM. Tetanus: a review of the literature. $B r \quad J$ Anaesth. 2001;87(3):477-487. doi:10.1093/bja/ 87.3.477

\section{Publish your work in this journal}

The International Medical Case Reports Journal is an international, peer-reviewed open-access journal publishing original case reports from all medical specialties. Previously unpublished medical posters are also accepted relating to any area of clinical or preclinical science. Submissions should not normally exceed 2,000 words or 4 published pages including figures, diagrams and references. The manuscript management system is completely online and includes a very quick and fair peer-review system, which is all easy to use. Visit http://www.dovepress.com/testimonials.php to read real quotes from published authors. 